\title{
Managing Restaurant Attributes for Destination Satisfaction: What Goes beyond Food?
}

\author{
Ezgi Erkmen ${ }^{(D)}$
}

School of Tourism and Hospitality, İstanbul Bilgi University, 34060 Eyüp/İstanbul, Turkey; ezgi.erkmen@bilgi.edu.tr

Received: 31 January 2019; Accepted: 22 February 2019; Published: 27 February 2019

check for updates

\begin{abstract}
Local cuisine has increasingly become one of the crucial factors contributing to how tourists experience a destination. As such, understanding which attributes affect travelers' experience of the local food is especially important to enhance tourist satisfaction. Therefore, the main purpose of this study is to determine the relative importance of different local cuisine experience attributes, as well as the perception of their performances. In doing so, Importance Performance Analysis (IPA) was conducted to assess tourists' perception. Data were collected from foreign travelers visiting Istanbul, Turkey, which is famous and well-known for its local cuisine. Furthermore, how different attributes affect destination satisfaction was analyzed via regression models. Interestingly, food-related cultural aspects and social aspects outweigh the food quality for their relative importance to travelers. Additionally, other than the physical environment, all attributes were found to contribute to tourists' satisfaction of the destination. Practical implications are provided in terms of how to promote and develop a competitive advantage by using local cuisine attributes for destination marketing.
\end{abstract}

Keywords: restaurant management; dining experience; local cuisine; destination marketing; IPA analysis

\section{Introduction}

In today's competitive world, destinations need to find different and unique ways to promote themselves. That is, travelers visiting a destination do not look for one specific experience, but seek a bundle of experiences. In other terms, destinations offer a holistic experience including accommodation, eating outside, communication with locals, visiting cultural sites, and so on (Ozturk and Qu 2008). Therefore, Morgan et al. (2002) argue that the core attributes of a destination need to be clearly identified to effectively promote a destination.

The significance of such thinking is further magnified within the context of dining experience, proposing local cuisine as a peak experience rather than a supporting experience (Quan and Wang 2004) contributing to tourists' satisfaction. This focus shift is specifically attributed to the fact that food does not only satisfy the basic need of tourists, but also represents a cultural element associated with a destination (Jenkins and Jones 2003). Similarly, many researchers have highlighted the importance of local food and cuisine for destinations (Boyne et al. 2002; Horng et al. 2012). Especially for developing alternative products for destinations, cuisines that are popular for their taste and quality could be a source of differentiation (Horng and Tsai 2010). A unique food identity helps to increase the competitiveness of a destination (Fox 2007). This is why destinations have started to use local food as a marketing and branding tool (Boyne and Hall 2004).

Considering the increased importance of local cuisine as a destination attribute, it is crucial to understand which factors contribute to the dining experience and how these factors influence travelers' satisfaction. This is so because previous studies have identified local cuisine experience as one of the significant sources of tourist satisfaction (Nield et al. 2000; Yüksel and Yüksel 2002; Kivela and 
Crotts 2006). Even though previous researchers have identified several attributes, namely the food quality, cultural aspects related to food, physical evidence, and social factors, as being the main factors affecting destination satisfaction (Jacobsen and Haukeland 2002; Namkung and Jang 2008; Jang and Namkung 2009; Ryu and Han 2010; Chang et al. 2011), there are only a limited number of studies analyzing the relative importance of each dining experience on destination satisfaction. Defined as consumers' post-purchase evaluation (Oliver 1980), satisfaction is usually explained by the expectation-disconfirmation theory of Lewin (1938). Mainly, the theory assesses satisfaction by comparing the actual performance with expectations. Thus, it is from this perspective that this study uses the Importance-Performance Analysis (IPA) technique, which assumes customer satisfaction to be an evaluation of actual performance with expectations.

More specifically, the main objectives of this study are to understand the relationship between the importance and performance of local cuisine dinning attributes, and to validate the effect of dining experience on destination satisfaction. In doing so, Turkey, with a well-known and highly emphasized local cuisine (Okumus et al. 2007), is selected to assess tourists' perception of dining experience and their satisfaction with the destination. Such an understanding will provide a better insight that can be used to manage and position the different local cuisine attributes. Moreover, with a growing emphasis on the role of local food in destination satisfaction, the findings will contribute to formulating more effective strategies for the promotion of destinations. Thus, destinations, as well as food service establishments, will be able to make better decisions to manage their resources more effectively.

\section{Review of Literature}

\section{Restaurant Attributes for Local Cuisine Experience and Destination Satisfaction}

With the introduction of experience economy by Pine and Gilmore (1998), tourist experience has become even more important to surviving in a highly competitive industry (Kim and Ritchie 2014). That is, memorable tourism experiences (MTEs) are integrated into the research to analyze antecedents of tourist satisfaction. Yuan (2009, p. 33) has defined tourism experience as "the total outcome involving a combination of customer's cognitive, affective, emotional, social, and physical responses gained from participating in activities and interacting with both tangible and intangible components in the consumption process, which in turn influences how consumers interpret the world". Since travel dining is also classified as a pleasurable sensory experience, including participation and interaction with tangible and intangible food-related attributes that affect tourists' satisfaction with a destination (Kivela and Crotts 2006), several studies have acknowledged the importance of local food in destination experience (Rust and Oliver 2000; Quan and Wang 2004; Ignatov and Smith 2006; Horng and Tsai 2010; Kim et al. 2010; Chang et al. 2011).

Given the commonly held view that local cuisine is a crucial part of travel experience, it is important to understand which factors contribute to the dining experience of travelers. Regarding the role of food consumption in tourism, the concept can be analyzed in four categories, which are "food as a tourist product/attraction, tourists' food consumption behaviour/pattern, tourists' dining experiences, and tourists' special interests in various food and beverages and related events/activities in destinations" (Mak et al. 2012, p. 176). In line with this categorization, for tourists' dining experience, Pendergast (2006) has also emphasized the role of food service establishments in shaping the overall destination experience. Therefore, this study adopts the third perspective and builds on the premise that tourists' dining experience in terms of restaurant attributes contributes to their satisfaction with the destination.

With respect to how food service establishment enhances local food experience, Nield et al. (2000) proposed food quality as the most important component of travel dining. Similarly, in the restaurant literature, many studies have identified food quality as the primary component of dining experience (Susskind and Chan 2000; Sulek and Hensley 2004; Namkung and Jang 2007). However, today, restaurants are not only responsible for serving quality food, but also for providing 
a unique tourist experience (Josiam et al. 2004). That is, to assure a unique experience, travel dining needs to be considered in a broader context. Hence, recent studies have started to reveal the other factors complementing the dining experience. According to Chang et al. (2011), besides food itself, authentically presented ambience, cultural sophistication of food, and employee service represent the important attributes affecting tourists' dining experience. Similarly, within the context of the restaurant industry, the overall dining experience is conceptualized as a function of three factors, namely the food, physical environment, and employee service (Jacobsen and Haukeland 2002; Namkung and Jang 2008; Jang and Namkung 2009; Ryu and Han 2010). With respect to the specific role of the suggested attributes, tastiness of food, menu variety, food presentation, serving size, and freshness are the most cited food-related factors representing the primary concern for diners (Kivela et al. 2000; Raajpoot 2002; Namkung and Jang 2007). Following food quality, the physical environment is suggested as the other attribute complementing the dining experience. Specifically, the physical environment, including music, lightening, design, layout, and social factors (Baker 1986), provides a tangible clue to assess the quality of a restaurant (Wall and Berry 2007). Furthermore, regarding local food experience, cultural sophistication of food is another factor that restaurants should take into account. As suggested by Richards (2003), authentic aspects of food represent a quality attribute expected by travelers experiencing cuisines specific to a location. Similarly, Okumus et al. (2007) have argued that local cuisine is a reflection of a destination heritage through an authentic cultural experience. Lastly, given the fact that service is the foundation of the hospitality industry, service quality has been suggested as the other main attribute of dining experience. Mostly conceptualized as assurance, empathy, and responsiveness of employees, service quality refers to employees' assistance, prompt service, and attention to customers (Stevens et al. 1995). However, Antun et al. (2010) have argued that just focusing on employee behaviors could hinder understanding the role of social factors in a service establishment. That is, social aspects including both employees and customers also represent an important factor to understand consumers' experience in a service setting.

This being the case, the role of attributes as being the source of satisfaction is further magnified in the context of destination marketing. How dining experience contributes to destination satisfaction could be better explained via looking at the origin of food experience. Based on the proposition of Dubé et al. (2003), dining experience arouses from four sources that are sensory, emotional, social, and intellectual. On one hand, local food enhances sensual indulgence via smell, taste, etc. On the other hand, it helps to provoke the emotional feelings of pleasure and joy. Additionally, dining experience also has its social origins of being together with friends, family, and others. Lastly, its intellectual origin refers to the memories of moments that are recalled. Therefore, since food-related experience has different sources of origin, previous studies have concluded that restaurant experience is one of the factors enhancing destination satisfaction (Nield et al. 2000; Björk and Kauppinen-Räisänen 2014). Hu and Ritchie (1993) identified food as the fourth most important factor affecting travelers' perception of a destination. Likewise, previous studies have found that food-related experiences positively affect tourist satisfaction with the destination (Nield et al. 2000; Yüksel and Yüksel 2002). Accordingly, while Sparks et al. (2003) highlighted the role of food service establishments for their contribution to overall satisfaction, Andersson and Mossberg (2004) have stressed the multidimensional nature of this experience. However, a limited number of studies have tried to understand these different dimensions (Andersson and Mossberg 2004; Kauppinen-Räisänen et al. 2013). Therefore, this study builds upon the view that visiting a destination is a holistic experience including different single unique experiences, which contribute to the overall travel experience (Björk and Kauppinen-Räisänen 2017) and the uniqueness of the experience refers to "experiencescapes" that are context-related (Mossberg 2007). This means that dining out in a restaurant could be considered one of the single experiences shaping the whole experiential outcome of the travel, which is the destination satisfaction. Specifically, local food adds value to travelers' travel experience, resulting in a higher level of satisfaction with a destination (Kivela and Crotts 2009). 
As a result, based on the previous theoretical foundations, this study adopted the twenty-two restaurant experience attributes (Wijaya 2014), which are identified to capture food quality, food-related cultural aspects, physical evidence, and social aspects to assess their role in explaining the restaurant experience, as well as to test the proposed relation between dining experience and destination satisfaction.

\section{Methods}

\subsection{Instrument and Measures}

The survey items for dining experience were obtained from the study of Wijaya (2014), which developed the items through existing literature on local cuisine experience. As a result, 22 items were identified to measure importance and performance perception regarding the local cuisine dining experience. To measure importance and performance satisfaction, the study used a Likert scale ranging from 1 to 5 points for "strongly unimportant" to "strongly important" and "strongly dissatisfied" to "strongly satisfied", respectively. The questions for destination satisfaction were adopted from a previous study of Chen and Phou (2013). The instrument contained four items that were my visit to İstanbul is worth my time and effort, compared to other destinations; İstanbul is a much better one; my experiences with İstanbul are excellent; and overall, I am satisfied with the travel experience in İstanbul.

\subsection{Sampling}

The target population of this research was the foreign travelers visiting İstanbul for leisure purposes to understand their perception of the dining experience and to analyze the effect of perceptions on destination satisfaction. The data was collected throughout the month of November in 2017 via a convenience sample of travelers. Even though the sampling method is nonprobability sampling, hindering the representativeness, the study met the recommendations for the $N: p$ ratio (Everitt 1975; Gorsuch 1983). Thus, convenience sampling was chosen due to its advantage of easily accessing the participants who met the criteria for the research (Walliman 2011). At the end, the study obtained 241 usable questionnaires for the data analysis.

\subsection{Data Analysis}

First, this study used the principal component factor method with VARIMAX rotation to generate underlying factors of 22 local cuisine experiences. Second, the proposed relationship for dining satisfaction and destination satisfaction was tested by a regression model using four factors of local cuisine experience as independent variables.

\section{Results}

First, principal factor analysis using VARIMAX rotation was used to generate underlying factors of dining attributes. The study retained the factors that have eigenvalues exceeding one. Moreover, regarding the cut-off value of factor loadings, the commonly used cut-off point of 0.40 was used to determine the significant attributes (Hair et al. 2006). At the end, 19 items were kept and four factors, namely the food quality, cultural food aspects, physical environment, and social aspects, were identified as the factors. The attributes and underlying factors are presented in Table 1. 
Table 1. Measurement items for local cuisine experience and underlying factors.

\begin{tabular}{|c|c|c|c|}
\hline & & Importance & Performance/Satisfaction \\
\hline \multicolumn{2}{|r|}{ Food Quality } & Mean & Mean \\
\hline FQ1 & Good taste of food & 3.18 & 3.98 \\
\hline $\mathrm{FQ} 2$ & The food to smell appealing & 3.47 & 3.68 \\
\hline FQ3 & Use fresh ingredients & 3.60 & 3.53 \\
\hline FQ4 & Original taste of food & 3.75 & 3.81 \\
\hline FQ5 & $\begin{array}{l}\text { Sense of belonging with local culture as a result } \\
\text { of food encounter }\end{array}$ & 3.95 & 3.32 \\
\hline \multicolumn{4}{|c|}{ Food Cultural Aspects } \\
\hline FC1 & The food to be presented attractively & 3.39 & 3.50 \\
\hline FC2 & Authentically spicy food & 3.45 & 3.75 \\
\hline FC3 & The food appeared unique and different & 4.72 & 3.55 \\
\hline FC4 & Culturally unique way of cooking the food & 4.04 & 3.58 \\
\hline FC5 & Culturally unique way of presenting the food & 4.92 & 3.36 \\
\hline FC6 & Culturally unique way of eating the food & 3.08 & 3.33 \\
\hline \multicolumn{4}{|c|}{ Physical Environment } \\
\hline PE1 & Ambiance of the dining place & 3.25 & 3.49 \\
\hline PE2 & Cleanliness & 3.02 & 3.38 \\
\hline PE3 & Culturally unique design, décor, and layout & 3.86 & 3.43 \\
\hline PE4 & Ambiance/atmosphere represents local culture & 3.79 & 3.47 \\
\hline PE5 & Staff are good at communication & 3.68 & 3.32 \\
\hline \multicolumn{4}{|c|}{ Social Aspects } \\
\hline SA1 & Staff friendliness & 3.59 & 3.42 \\
\hline SA2 & Staff responsiveness to specific needs & 3.68 & 3.47 \\
\hline SA3 & $\begin{array}{l}\text { Other customers in dining area help to enjoy } \\
\text { local food and culture }\end{array}$ & 3.88 & 3.49 \\
\hline
\end{tabular}

With respect to importance, the main food-related concern is to feel a "sense of belonging with local culture as a result of food encounter" $(\mathrm{M}=3.95, \mathrm{SD}=1.08)$. Of the other items, "original taste of the food" has the second rank among respondents. That is, food quality is associated with the food being traditional and original. On the other hand, for the food cultural aspect, the most important attribute rated by the respondents is "culturally unique way of presenting food" (M=4.92 SD =1.70), followed by "the food appeared unique and different" and "culturally unique way of cooking the food", respectively. Regarding the physical environment, the main concern of respondents is "culturally unique design, décor, and layout" ( $\mathrm{M}=3.86, \mathrm{SD}=1.11)$. Other than that, the ambiance of the restaurant reflecting local culture is rated as the second most important item for the physical environment. Lastly, for social aspects, "other customers help to enjoy local food and culture" is rated as the most important attribute $(\mathrm{M}=3.88, \mathrm{SD}=1.05)$. Besides the importance of items under each factor, the study found food cultural aspects to be the most important factor for local cuisine experience, followed by social aspects, food quality, and the physical environment. Hence, as suggested by López-Guzmán and Sánchez-Cañizares (2012), international travelers are mostly interested in experiencing traditional and cultural attributes of a location. That is, tourists give importance to local cuisine experience to reflect local culture and traditions for all dimensions of dinning.

On the other hand, regarding the satisfaction of travelers, the performance of food establishments was below the expectations for food cultural aspects, the physical environment, and social aspects. Only the food quality was found to exceed the importance score by showing a higher performance than expectations. Thus, as argued by previous research (Richards 2003), restaurants should go beyond food quality to enhance satisfaction by reflecting traditional and local aspects in every dimension of the dining experience, including the service, and physical and social environment.

After determining the factors and underlying attributes, IPA analysis was conducted to understand the relation between the importance and performance of these items. The mean scores of 19 dining experience attributes for importance and performance were transferred to an analytical axis. 
While the $Y$-axis represents the importance scores, the $X$-axis represents the performance (satisfaction) scores for local cuisine dining experience. The results of IPA analysis for both factors and attributes are provided in Figures 1 and 2, respectively.

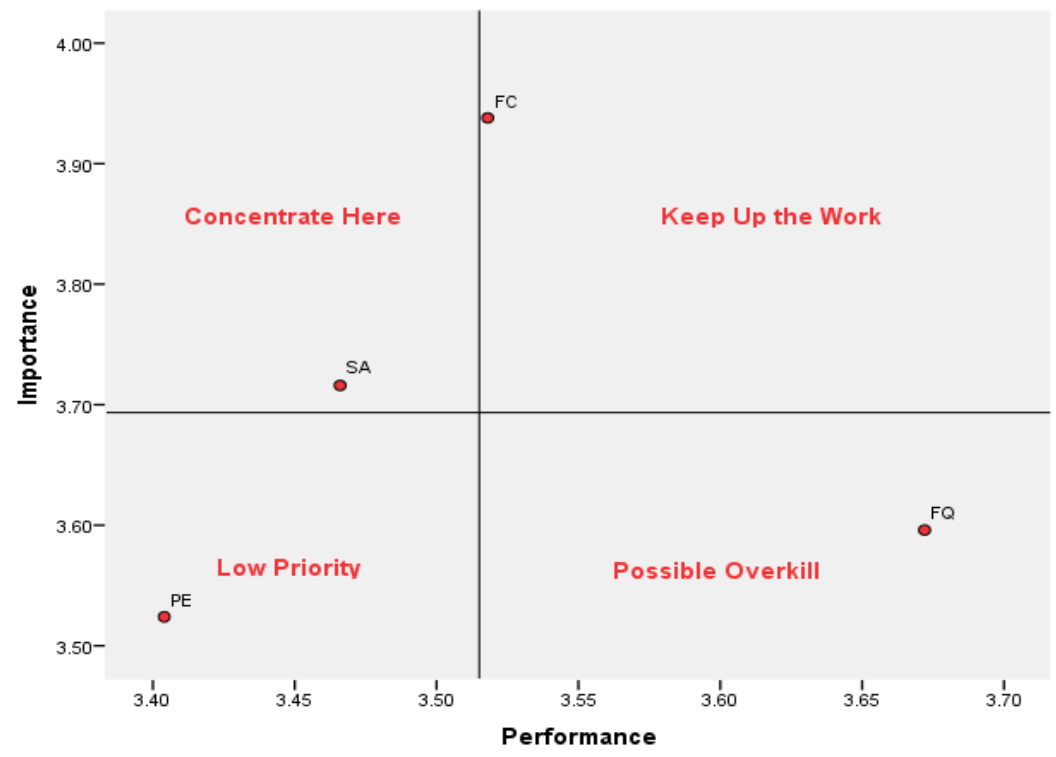

Figure 1. Results of IPA analysis for factors.

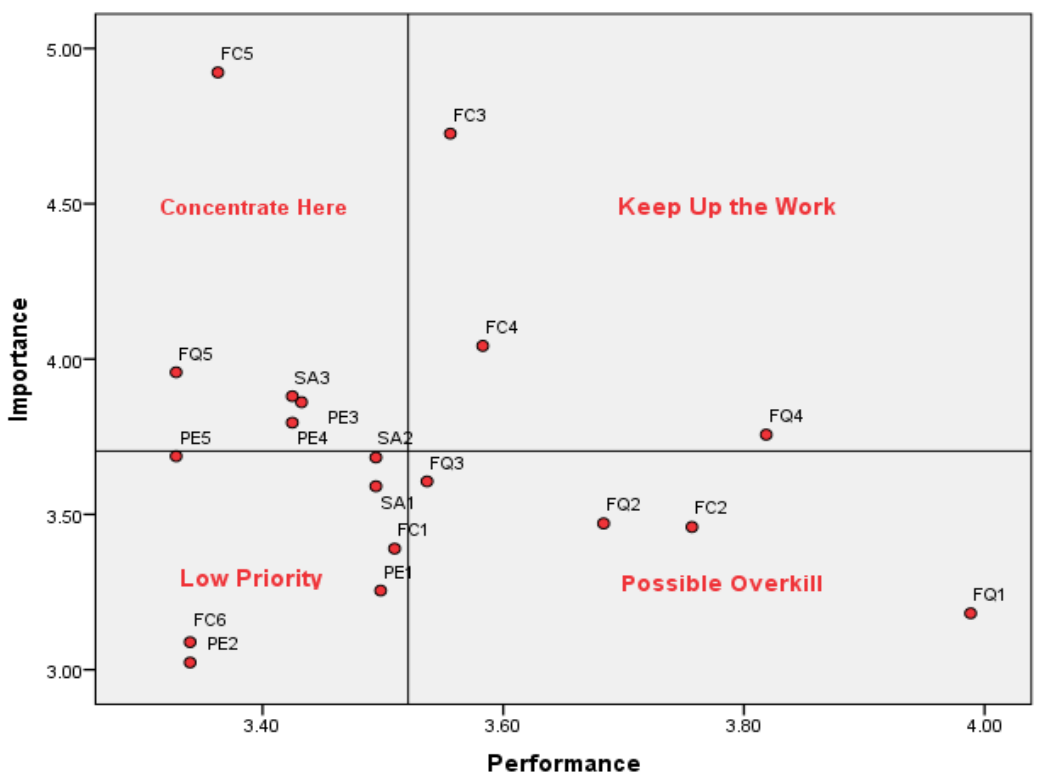

Figure 2. Results of IPA analysis for attributes.

As seen in Figure 1, food cultural aspects fall into the quadrant of "keep up the work" as a result of being evaluated as high for both importance and satisfaction. Hence, food cultural aspects may represent opportunities for a competitive advantage. Regarding food quality, the performance was above the expectations of the respondents locating the factor in the quadrant of "possible overkill". This result implies that it would be better for dining establishments to concentrate on other factors rather than committing all their effort to food quality. On the other hand, social aspects located in the quadrant of "concentrate here", are rated high for importance but low for performance, suggesting that resources and effort are devoted to improving the social aspects of the dining experience. Lastly, the physical environment falls into the quadrant of "low priority", implying low importance of the factor for dining experience. 
Even though the factors were analyzed for their overall scores of importance and performance, this study also investigated the specific position of each attribute via IPA analysis. As shown in Figure 2, the destinations and food establishments should devote their efforts to improving their ambiance to reflect local culture, as well as the communication skills of the employees. Actually, the communication ability of the employees is the highest evaluated attribute regarding employee skills. Furthermore, the presentation of local food and food encounter need to be developed to enhance the sense of belonging to local culture. On the other hand, three attributes, namely the food appearance, culturally unique way of cooking the food, and original taste of food, could be used to position the local cuisine and gain a competitive advantage.

Lastly, this study used a regression model to test the proposed relationship between local cuisine experience and destination satisfaction. Four factors were used as independent variables to understand their effect on destination satisfaction. The overall model was found to be significant at $0.01(\mathrm{~F}=$ $47.738, p<0.01)$. The model explained $42.9 \%$ of the variance for destination satisfaction, with an $\mathrm{R}^{2}$ value of 0.429 . Specifically, the model indicated that food quality ( $\beta=0.218, p<0.01$ ), food cultural aspects $(\beta=0.352, p<0.01)$, and social aspects $(\beta=0.223, p<0.01)$ positively affected the destination satisfaction of travelers. Among these factors, "food cultural aspects" was the most relevant factor for satisfaction. On the other hand, this study could not evidence a significant effect for the physical environment. A summary of regression analysis is provided in Table 2.

Table 2. Regression Analysis Summary for Dining Experience Attributes Predicting Destination Satisfaction.

\begin{tabular}{cccc}
\hline Variable & Standardized Coefficients $(\boldsymbol{\beta})$ & $\boldsymbol{t}$-Value & Sig. \\
\hline Food Quality & 0.218 & 4.161 & 0.000 \\
\hline Food Cultural Aspects & 0.352 & 6.667 & 0.000 \\
\hline Physical Environment & 0.108 & 1.793 & 0.074 \\
\hline Social Aspects & 0.223 & 3.932 & 0.000 \\
\hline & $R^{2}=0.429,(N=241, p<0.001)$ & & \\
\hline
\end{tabular}

\section{Discussion and Implications}

\subsection{Discussion of the Findings}

This study has tried to understand the relationship between the importance and performance (satisfaction) of local cuisine experience, as well as examine the effect of dining experience on destination satisfaction. Regarding the importance factors for dining experience, the most important factor for travelers is the food cultural aspects. Specifically, tourists expect local food to reflect unique cultural aspects for cooking, presentation, and appearance. Following cultural aspects, social aspects, which are employees and other customer behaviors, are the second most important factor for foreign travelers. As the third important factor, food quality followed the social aspects. Lastly, the physical environment has been rated as the least important factor for dining experience.

Other than importance, respondents have also evaluated their satisfaction with each factor. As the IPA analysis shows, food establishments demonstrate a high performance for food quality and food cultural aspects. However, food quality is not rated as being as important as food cultural aspects. Hence, food cultural aspects represent a point of differentiation for local restaurants. That is, both destination organizations and food establishments need to focus on cultural aspects of food and position the local cuisine through emphasizing unique aspects of food. The other important finding of this research relates to social aspects. Even though respondents rate social aspects as important, their satisfaction level was low for this factor. This result implies that food establishments need to focus more on the service behaviors of employees. Lastly, the physical environment has been found to have a low priority for dining establishments. That is, destinations and restaurateurs should direct 
their resources and effort to developing their employees' behavior and to positioning the local cuisine around culturally unique aspects of food.

With respect to the effect of local cuisine experience on destination satisfaction, the findings also validate the positive effect of food, cultural aspects related to food, and social aspects. On the other hand, being the low priority factor, the physical environment does not have any significant influence on the satisfaction of travelers with the destination. Consequently, this study has evidenced the contribution of local cuisine experience to the destination satisfaction.

\subsection{Implications of the Findings}

The findings of the research imply that, from the perspective of local food establishments as well as destination management organizations, destinations need to understand the relative importance and performance of dining attributes and to manage these attributes accordingly. In particular, the results suggest that tourists give more importance to contextual factors, especially to the cultural aspects related to the food. As such, destination marketers and food service establishments should capitalize on the cultural aspects of local cuisine in promoting the destination, as well as their culinary establishments. Since local food is increasingly becoming crucial to differentiate and position the destinations (Horng and Tsai 2010), local cuisine could be used to create a unique brand image of the destination, which in turn affects future behavioral intentions of travelers (Horng et al. 2012). Therefore, destination management organizations may promote the food-related cultural aspects, such as appearance, presentation, and unique ways of cooking the food, to improve the contribution of local cuisine to the destination brand image. Moreover, the destination brand results from associations with the destination (Kotler and Gertner 2002). As such, destinations known for their local cuisine could use local food as a key association to promote the distinctiveness of themselves. Hence, images of food can be used as a means of promotion. As suggested by Rand et al. (2003), how restaurants and local cuisine are presented in promotional materials provides important clues about food experience in a destination. It is from this perspective that visual images of food, its presentation, and cooking styles should be highlighted in all marketing materials of a destination. That is, the authenticity of food should be heavily used in marketing.

Additionally, as validated by the findings, social aspects represent an important attribute that travelers pay attention to when determining their overall dining experience. Accordingly, the restaurateurs should focus on the skills and abilities of their service employees. In particular, employees should be good in terms of their communication skills and their service behaviors. Additionally, service personnel need to be knowledgeable about the menu items regarding their ingredients, or even their stories. Since food reflects the culture of a destination, specific knowledge about the local cuisine should be the priority for service employees.

Besides being used as a promotional tool, local cuisines could help destinations to diversify the tourism offerings, as well as create an economic impact. That is, the regions in a destination having distinguished and famous cuisines could be promoted as gastronomic regions. In doing so, destinations could both increase their tourism offerings and contribute to the economic development of local areas. In addition, these areas could be turned into main attraction areas with events and festivals.

With respect to the diversification of tourism offerings, local cuisine contributes to diverse positioning efforts of a destination. Specifically, local cuisine may help to attract travelers whose major motivation is to experience different cuisines and cultures. Thus, culinary tourists could be targeted as an alternative market segment for the destination. In turn, destinations could increase both the number of travelers and tourism earnings.

Furthermore, as a means to identify itself in contrast to other competitive destinations, local cuisine identity may enhance the brand identity of a destination. A distinguished local food identity could help to gain long-term advantages. That is, satisfaction with the local cuisine affects the future behavioral intentions (Horng and Tsai 2010). It is from this perspective that, by creating a unique cuisine identity, destinations increase the number of travelers by repeat visits and positive word of 
mouth. Regarding the findings of this study, the unique food identity may be created along cultural aspects of local cuisine. Symbolic characteristics of food should be promoted beyond the food itself. Even though the core identity is the food, the unique characteristics, the cooking, presentation, and appearance, should be highlighted when marketing local food.

To sum up, local cuisine experience has become an important part of overall destination experience affecting travelers' satisfaction with the destination. Therefore, as suggested by the study results, promoting local cuisine may contribute to creating memorable experiences for tourists that affect their future behavioral intentions. In turn, destinations could increase the number of travelers, as well as their tourism earnings. Moreover, destinations may have the opportunity to position themselves more effectively and to increase their competitive advantage. It is from this perspective that local food could offer an alternative product and positioning for destinations, if the dining experience of travelers is well-understood and -managed.

Author Contributions: As the sole contributor, the author designed the study, conducted the analysis, and wrote the manuscript.

Funding: This research received no external funding.

Conflicts of Interest: The author declares no conflict of interest.

\section{References}

Andersson, Tommy D., and Lena Mossberg. 2004. The dining experience: Do restaurants satisfy customer needs? Food Service Technology 4: 171-77. [CrossRef]

Antun, John M., Robert E. Frash, Wanda Costen, and Rodrey C. Runyan. 2010. Accurately assessing expectations most important to restaurant patrons: The creation of the DinEX Scale. Journal of Foodservice Business Research 13: 360-79. [CrossRef]

Baker, Julie. 1986. The role of the environment in marketing services: The consumer perspective. The Services Challenge: Integrating for Competitive Advantage 1: 79-84.

Björk, Peter, and Hannele Kauppinen-Räisänen. 2014. Culinary-gastronomic tourism-a search for local food experiences. Nutrition and Food Science 44: 294-309. [CrossRef]

Björk, Peter, and Hannele Kauppinen-Räisänen. 2017. Interested in eating and drinking? How food affects travel satisfaction and the overall holiday experience. Scandinavian Journal of Hospitality and Tourism 17: 9-26. [CrossRef]

Boyne, Steven, and Derek Hall. 2004. Place promotion through food and tourism: Rural branding and the role of websites. Place Branding 1: 80-92. [CrossRef]

Boyne, Steven, Fiona Williams, and Derek Hall. 2002. On the trail of regional success: Tourism, food production and the Isle of Arran Taste Trail. In Tourism and Gastronomy. London: Routledge, pp. 91-114.

Chang, Richard C., Jaksa Kivela, and Athena H. N. Mak. 2011. Attributes that influence the evaluation of travel dining experience: When East meets West. Tourism Management 32: 307-16. [CrossRef]

Chen, Ching-Fu, and Sambath Phou. 2013. A closer look at destination: Image, personality, relationship and loyalty. Tourism Management 36: 269-78. [CrossRef]

Rand, Gerrie E., Heath Ernie, and Nic Alberts. 2003. The role of local and regional food in destination marketing: A South African situation analysis. Journal of Travel \& Tourism Marketing 14: 97-112.

Dubé, Laureted, Jordan Le Bel, and Dodna Sears. 2003. From customer value to engineering pleasurable experiences in real life and online. Cornell Hotel and Restaurant Administration Quarterly 44: 124-30. [CrossRef]

Everitt, Brian S. 1975. Multivariate analysis: The need for data, and other problems. British Journal of Psychiatry 126: 237-40. [CrossRef] [PubMed]

Fox, Renata. 2007. Reinventing the gastronomic identity of Croatian tourist destinations. International Journal of Hospitality Management 26: 546-59. [CrossRef]

Gorsuch, Richard L. 1983. Factor Analysis. Hillsdale: Erlbaum.

Hair, Joseph F., William C. Blac, Barry J. Babin, Rolph E. Anderson, and Ronald Tatham. 2006. Multivariate Data Analysis. Upper Saddle River: Prentice Hall.

Horng, Jeou-Shyan, and Chang-Yen Tsai. 2010. Government websites for promoting East Asian culinary tourism: A cross-national analysis. Tourism Management 31: 74-85. [CrossRef] 
Horng, Jeou-Shyan, Chih-Hsing Liu, Hsin-Yu Chou, and Chang-Yen Tsai. 2012. Understanding the impact of culinary brand equity and destination familiarity on travel intentions. Tourism Management 33: 815-24. [CrossRef]

$\mathrm{Hu}$, Yangzhou, and J. R. Brent Ritchie. 1993. Measuring destination attractiveness: A contextual approach. Journal of Travel Research 32: 25-34.

Ignatov, Elena, and Stephen Smith. 2006. Segmenting Canadian culinary tourists. Current Issues in Tourism 9: 235-55. [CrossRef]

Jacobsen, Jens K. Steen, and Jan Vidar Haukeland. 2002. A lunch with a view: Motor tourists' choices and assessments of eating-places. Scandinavian Journal of Hospitality and Tourism 2: 4-16. [CrossRef]

Jang, SooCheong Shawn, and Young Namkung. 2009. Perceived quality, emotions, and behavioral intentions: Application of an extended Mehrabian-Russell model to restaurants. Journal of Business Research 62: 451-60. [CrossRef]

Jenkins, Ian, and Andrew Jones. 2003. A Taste of Wales-Blas Ar Gymru': Institutional malaise in promoting Welsh food tourism products. In Tourism and Gastronomy. London: Routledge, pp. 129-45.

Josiam, Bharath M., Melissa Mattson, and Pauline Sullivan. 2004. The Historaunt: Heritage tourism at Mickey's dining car. Tourism Management 25: 453-61. [CrossRef]

Kauppinen-Räisänen, Hannele, Johanna Gummerus, and Katariina Lehtola. 2013. Remembered eating experiences described by the self, place, food, context and time. British Food Journal 115: 666-85. [CrossRef]

Kim, Jong-Hyeong, and J. R. Brent Ritchie. 2014. Cross-cultural validation of a memorable tourism experience scale (MTES). Journal of Travel Research 53: 323-35. [CrossRef]

Kim, Yeong Gug, Bo Won Suh, and Anita Eves. 2010. The relationships between food-related personality traits, satisfaction, and loyalty among visitors attending food events and festivals. International Journal of Hospitality Management 29: 216-26. [CrossRef]

Kivela, Jaksa, and John C. Crotts. 2006. Tourism and gastronomy: Gastronomy's influence on how tourists experience a destination. Journal of Hospitality $\mathcal{E}$ Tourism Research 30: 354-77.

Kivela, Jaksa J., and John C. Crotts. 2009. Understanding travellers' experiences of gastronomy through etymology and narration. Journal of Hospitality E Tourism Research 33: 161-92.

Kivela, Jakia, Robert Inbakaran, and John Reece. 2000. Consumer research in the restaurant environment. Part 3: Analysis, findings and conclusions. International Journal of Contemporary Hospitality Management 12: 13-30. [CrossRef]

Kotler, Philip, and David Gertner. 2002. Country as brand, product, and beyond: A place marketing and brand management perspective. Journal of Brand Management 9: 249-61. [CrossRef]

Lewin, Kurt. 1938. The Conceptual Representation and Measurement of Psychological Forces. Durham: Duke University Press.

López-Guzmán, Tomas, and Sandra Sánchez-Cañizares. 2012. Culinary tourism in Córdoba (Spain). British Food Journal 114: 168-79. [CrossRef]

Mak, Athena H. N., Margaret Lumbers, and Anita Eves. 2012. Globalization and food consumption in tourism. Annals of Tourism Research 39: 171-96. [CrossRef]

Morgan, Nigel, Annette Pritchard, and Rachel Piggott. 2002. New Zealand, 100\% pure. The creation of a powerful niche destination brand. Journal of Brand Management 9: 335-54. [CrossRef]

Mossberg, Lena. 2007. A marketing approach to the tourist experience. Scandinavian Journal of Hospitality and Tourism 7: 59-74. [CrossRef]

Namkung, Young, and SooCheong Jang. 2007. Does food quality really matter in restaurants? Its impact on customer satisfaction and behavioral intentions. Journal of Hospitality $\mathcal{E}$ Tourism Research 31: 387-409.

Namkung, Young, and SooCheong Jang. 2008. Are highly satisfied restaurant customers really different? A quality perception perspective. International Journal of Contemporary Hospitality Management 20: 142-55. [CrossRef]

Nield, Kevin, Metin Kozak, and Geoffrey LeGrys. 2000. The role of food service in tourist satisfaction. International Journal of Hospitality Management 19: 375-84. [CrossRef]

Okumus, Bendegul, Fevzi Okumus, and Bob McKercher. 2007. Incorporating local and international cuisines in the marketing of tourism destinations: The cases of Hong Kong and Turkey. Tourism Management 28: $253-61$. [CrossRef]

Oliver, Richard L. 1980. A cognitive model of the antecedents and consequences of satisfaction decisions. Journal of Marketing Research 17: 460-69. [CrossRef] 
Ozturk, Ahmet Bulent, and Hailin Qu. 2008. The impact of destination images on tourists' perceived value, expectations, and loyalty. Journal of Quality Assurance in Hospitality E Tourism 9: 275-97.

Pendergast, Donna. 2006. Tourist gut reactions: Food safety and hygiene issues. In Tourism in Turbulent Times: Towards Safe Experiences for Visitors. Edited by Jeff Wilks, Donna Pendergast and Peter Leggat. Oxford: Elsevier, pp. 143-54.

Pine, B. Joseph, and James H. Gilmore. 1998. Welcome to the experience economy. Harvard Business Review 76: 97-105. [PubMed]

Quan, Shuai, and Ning Wang. 2004. Towards a structural model of the tourist experience: An illustration from food experiences in tourism. Tourism Management 25: 297-305. [CrossRef]

Raajpoot, Nusser A. 2002. TANGSERV: A multiple item scale for measuring tangible quality in foodservice industry. Journal of Foodservice Business Research 5: 109-27. [CrossRef]

Richards, Greg. 2003. Gastronomy: An essential ingredient in tourism production and consumption? In Tourism and Gastronomy. London: Routledge.

Rust, Roland T., and Richard L. Oliver. 2000. Should we delight the customer? Journal of the Academy of Marketing Science 28: 86-94. [CrossRef]

Ryu, Kisang, and Heesup Han. 2010. Influence of the quality of food, service, and physical environment on customer satisfaction and behavioral intention in quick-casual restaurants: Moderating role of perceived price. Journal of Hospitality \& Tourism Research 34: 310-29.

Sparks, Beverly, John Bowen, and Stefanie Klag. 2003. Restaurants and the tourist market. International Journal of Contemporary Hospitality Management 15: 6-13. [CrossRef]

Stevens, Pete, Bonnie Knutson, and Mark Patton. 1995. DINESERV: A tool for measuring service quality in restaurants. Cornell Hotel and Restaurant Administration Quarterly 36: 56-60. [CrossRef]

Sulek, Joanne M., and Rhonda L. Hensley. 2004. The relative importance of food, atmosphere, and fairness of wait: The case of a full-service restaurant. Cornell Hotel and Restaurant Administration Quarterly 45: 235-47. [CrossRef]

Susskind, Alex M., and Edwin K. Chan. 2000. How Restaurant Features Affect Check Aberages: A Study of the Toronto Restaurant Market. Cornell Hotel and Restaurant Administration Quarterly 41: 56-63. [CrossRef]

Wall, Eileen A., and Leonard L. Berry. 2007. The combined effects of the physical environment and employee behavior on customer perception of restaurant service quality. Cornell Hotel and Restaurant Administration Quarterly 48: 59-69. [CrossRef]

Walliman, Nicholas. 2011. Research Methods: The Basics. New York: Routledge.

Wijaya, Serli. 2014. Encounters with Local Food: The Culinary Experiences of International Visitors in Indonesia. Ph.D. Dissertation, Victoria University, Melbourne, Australia.

Yuan, Y. H. 2009. The Nature of Experience in Hospitality Settings. Ph.D. Dissertation, Texas Tech University, Lubbock, TX, USA.

Yüksel, Atilla, and Fisun Yüksel. 2002. Market segmentation based on tourists' dining preferences. Journal of Hospitality \& Tourism Research 26: 315-31.

(C) 2019 by the author. Licensee MDPI, Basel, Switzerland. This article is an open access article distributed under the terms and conditions of the Creative Commons Attribution (CC BY) license (http://creativecommons.org/licenses/by/4.0/). 